\title{
Learning in the living campus - remotely sensing activities correlated to learning in outdoor spaces
} \author{
aprendizagem em espaços ao ar livre \\ - Carlos Eduardo Verzola Vaz \\ UFPE, Brazil \\ Thomas Kvan \\ cevv00@gmail.com \\ University of Melbourne, Australia \\ tkvan@unimelb.edu.au \\ - Justyna Anna Karakiewicz \\ University of Melbourne, Australia \\ justynak@unimelb.edu.au
}

Aprendizado no projeto "living campus"- utilizando o sensoriamento remoto para compreender atividades correlacionadas à

\begin{abstract}
This paper presents preliminary results of a research that seeks to develop an algorithmic model to represent how campus users interact with one another, as well with the surrounding environment, in order to comprehend the dynamics of activities that can be correlated to learning in open spaces and thus develop design guidance for such spaces. The hypothesis is that learning activities in outdoor spaces is also responsible to contribute to the life of the academic purpose of the campus, and that this can then inform design decisions for such spaces to better support outdoor informal learning. During the research, video recording and interviews were used to collect data and identify patterns of behavior in three research sites in the University of Melbourne.
\end{abstract}

Keywords: Open Spaces, Learning, Remote Sensing, Computer Vision

\section{INTRODUCTION}

The campus landscape defines the campus's spaces, providing the great outdoor rooms and places in which the campus community interacts. The importance of the campus open spaces for meeting, for education, for contemplation, and for communal activities cannot be overstated... (Kenney, 2005)

On a university campus, we can expect that learning will take place in both indoor spaces and outdoor spaces. The first set of learning environments consists of enclosed spaces, such as classrooms, lecture theatres, laboratories, libraries, corridors, etc. The second set of environments that can support learning consists of open spaces, such as quadrangles, courtyards, plazas, pedestrian pathways, etc. As universities develop learning places for students, attention must be focused on both indoor and outdoor places. Nevertheless, design guides are plentiful for the design of indoor learning spaces but few are available for outdoor spaces (Jamieson, 2003).

In contrast to indoor spaces, learning in outdoor spaces is a more casual activity, within which countless patterns of learning activities might emerge. For example, students may work in a group around a garden table, read assigned texts in print or a mobile device while lying on the lawn or have a conversation about a lecture subject while sharing a bench. These learning activities may be interspersed among non-learning activities, such as revisiting a sports match. Therefore, it becomes a challenge to differentiate those activities that are related to learning from the ones that are mainly recreational, especially as we cannot infer the activity through the nature of the space as we might for a classroom. Consequently, it is challenging to recognize specific activities correlated to learning in outdoor spaces and to identify the combination of parameters that support this.

Spaces for learning are usually developed for specific activities and have, as was explained, a much more controlled environment. In a university library, temperature, luminosity and noise are normally regulated to give users a perfect atmosphere for focused studying. Designers can organize spaces in different ways, giving students different levels of privacy. For instance, in a library one can find long tables with more than six chairs, forming small groups. However, some of these spaces are not for talking, because the table is wide enough to create an atmosphere of privacy, even if the student is sitting next to a colleague.

Libraries also have specific spaces for studying alone, such as single chair tables, which may or may not be isolated in small rooms. In a classroom, spaces and environment can also be designed to create a perfect atmosphere for learning. In this case, according to Cleveland (2011), pedagogy has an important role in the definition of spatial organization. The 
designer, for instance, can arrange furniture in different ways according to a student or teacher centered learning pedagogy. The spatial arrangement, and the way the teacher or lecturer guides students during the learning process, will influence students' behaviour inside a classroom.
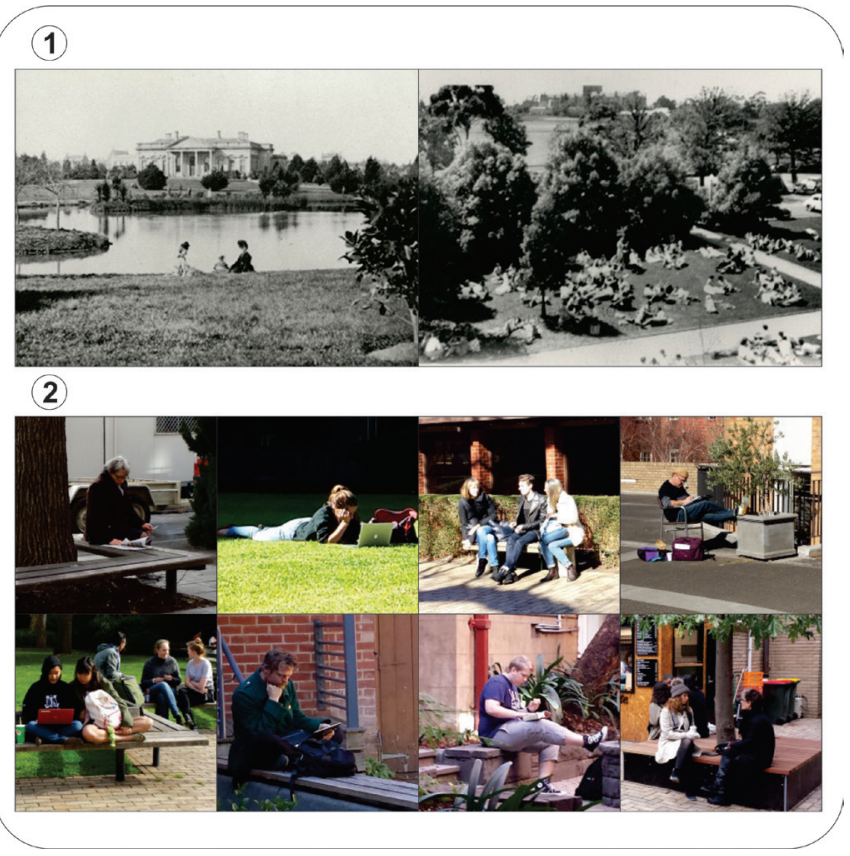

Figure 1: (1-left) Old Medical building with lake and lawns in foreground, University of Melbourne; (1-right) Looking down from the Union roof at lunchtime, University of Melbourne, 3rd term 1951. (2) Recent images of users in different situations in the campus outdoor spaces. Source: (1) University of Melbourne Archives (UMA/1/2162); (2) Created by the author.

However, Kenney (2005) believes that students can learn wherever they have opportunity for interaction, and that every part of a campus must be considered a learning environment, with anything less being a missed opportunity. Nevertheless, sometimes, decisions taken during the planning process do not look to outdoor spaces as places to amplify interaction between students and boost the sense of community in a university's campus.

Evidently, the degree of importance of outdoor space during the learning process relies on different aspects. For instance, the location of a campus and the site's climate can be considered important factors that may guide decisions and investments. Technology can also be an enabler of community and education, as well as a factor in increasing isolation. According to Kenney (2005), students were comfortable accessing information and communicate using computers. In his study, this access was generally achieved in a private way, using a network connection in the student room. However, the author also states that in 2005 studentlife professionals were beginning to put priority on places where people can interact. Today, the increasing prevalence of wireless and mobile technologies are allowing students to consume information and interact virtually with friends while in public spaces.

This paper presents preliminary results of research to develop an algorithmic model to represent how campus users interact with one another, as well with the surrounding environment, in order to examine the dynamics of learning activities in open spaces and thus develop design guidance for such spaces. The research hypothesis is that learning activities in outdoor spaces contribute to the life of the academic purpose of the campus, and that this can then inform design decisions for such spaces to better support outdoor informal learning. The investigation process seeks to answer the following research questions:

1. Is it possible to find a correlation between learning activity and behaviour in outdoor spaces?

2. Can we interpret a learning activity through patterns of activity observed by remote sensing?

3. How do environmental parameters and spatial arrangements influence the dynamics of learning activities in outdoor spaces?

Comprehension about the importance of learning in outdoor spaces can lead to infrastructure that can assist the campus manager during decision-making, helping to predict what kind of change will occur in the campus as a whole. Such a model can then be used to simulate activity in new designs for spaces and postulate user activity in these spaces. The contribution to knowledge in this research do not come from the tools used or developed over the research process, but the strategy used to attempt to comprehend learning phenomena in outdoor space.

\section{METHODOLOGICAL APPROACH}

The goal in this research is to use a case study (Wang and Groat, 2002) strategy to identify and describe students' behavior in a public place located in the University of Melbourne. Three places located around the school of design were defined as sites for the research: the outdoor spaces situated adjacent to the north, south and west façades of the building. These spaces have benches arranged in a variety of spatial configurations and a grass lawn that allows users to sit alone, or in small or large groups. In addition, the chosen sites allow the emergence of countless patterns of interaction, thus working as a good representation of how the campus community uses outdoor spaces.

The research has been developed in three main phases: (1) data collection, (2) data analysis and (3) development of remote sensing prototypes.

In the first phase, three methods were used to collect data from the research site: video recording, interviews and naturalistic observations. In the data analysis phase interviews and observations were used to make a correlation between patterns of activity identified in the research site 
and learning. For instance, is it possible for the researchers to correlate other factors with the reading activity that the user is doing and learning? Is it possible to correlate learning and the group of people talking informally during lunchtime? In the third phase, prototypes were developed to remotely sense users, using a camera as the source of data and post processing based on computer vision approaches.

\section{Video data collection for urban life studies}

Gehl (2013) explains that photographs can be widely used in the field of public life studies to illustrate situations, showing the interaction between urban form and life, and to document the character of a site before and after a redeveloping initiative. The author explain that while the human eye can observe and register, photographs and film are good aids for communication and can be a good tool for fast-freezing situations for later documentation and analysis. By later studying photographs or film, it is possible for a designer or researcher to identify patterns of behavior, or go into detail with otherwise complex city situations that are difficult to fully process and analyze with only a single glance.

Gehl also states that different variations of video recording can be used to study urban settings, such as timelapse photography or video sequences to show situations over time, with or without the presence of the observer. The angle and size of the lens is relevant if either film or photograph is to correspond to the human field of vision. An emblematic use of video capturing can be found in Whyte (1980)'s seminal work to analyze human behavior in outdoor spaces to understand social life in urban settings. In his research, the author extensively used observation and image capturing to collect data about people flow and behave in New York public spaces, using mounted time-lapse cameras overlooking plazas as tools to record daily patterns of use. His research group talked to people to try to discover their origin and subsequent destination, where they worked, the place frequency use, and what they thought of it.

The studies developed in the urban field by Whyte (1980) and Gehl (2013) were based on manual post processing analyses. However, in the last two decades, computer vision is becoming a much more accessible field, with free libraries and tools developed to automatically process images, allowing the creation of applications capable of influencing, managing,to manage direct, or protect citizens. This technology has been widely used to understand human events such as motion, crowd analyses, etc.

Moeslund and Granund (2001) states that the potential applications of human motion capture are the dynamic field of system development, and they consider the following three major application areas: surveillance, control, and analysis. The authors explains that the surveillance area uses applications where one or more subjects can be tracked over time and possibly monitored for specific actions. The authors uses as classic example the surveillance of a parking

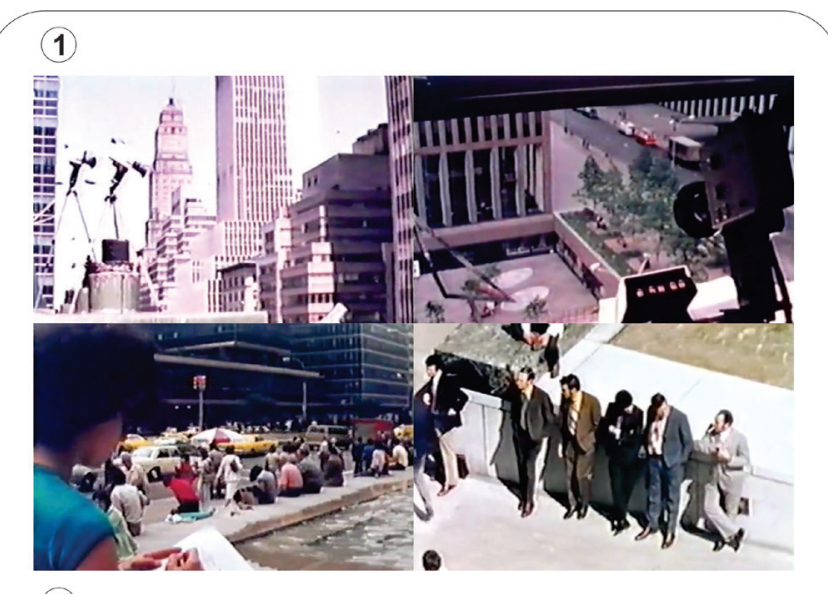

(2)

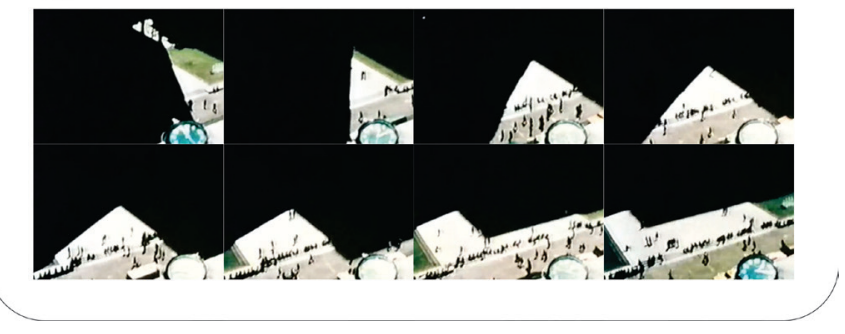

Figure 2: (1) Images captured from Whyte's documentary (The social life of small urban Spaces, 1988) showing mounted cameras in a building roof and researchers collecting information about users in a plaza in Manhattan. (2) Shot sequence also collected from Whyte documentary showing a plaza usage during the day, focusing on the relation between direct and indirect light and density of users. Source: Created by the author from Whyte's materials.

lot, where a system tracks subjects to evaluate whether they may be about to commit a crime, e.g., steal a car. The control area relates to applications where the captured motion is used to provide controlling functionalities. It could be used as an interface to games, virtual environments, or animation or to control remotely located implements. The third application area is concerned with the detailed analysis of the captured motion data. This may be used, according to the authors, in clinical studies for diagnostics of orthopedic patients or to help athletes understand and improve their performance.

In urban design studies, it is also possible to notice a potential growth of implementations using computer vision strategy. Zhan, Monekosso, Remagnino, Velastin and $\mathrm{Xu}$ (2008) explain that the continuous population growth and the rapid urbanization process around the world, has made the crowd phenomenon more frequent in our cities. According to this context, the authors state that it is not surprising, therefore, that crowd analysis has been receiving more consideration from technical and social research disciplines. According to the authors, a large number of applications have been developed, mainly focusing on the following subjects:

1. Crowd management: Development of crowd management strategies to avoid disaster and ensure public safety in more popular and frequent event such as sport 
matches, large concerts and public demonstrations;

2. Public space design: Crowd analysis can provide guidelines for the design of public spaces;

3. Virtual environments: Mathematical models of crowds can be applied in virtual environments to improve the simulation of crowd phenomena and enrich the human life experience.

4. Visual surveillance: Crowd analysis can be used for automatic detection of anomalies and alarms. Furthermore, the ability to track individuals in a crowd can be used as a tool in suspect recognition;

5. Intelligent environments: In some intelligent environments, which involve large groups of people, crowd analysis is a pre-requisite for assisting the crowd or an individual to take a decision.

In the case of our study, the goal is to use video processing to develop prototypes to identify students' behavior automatically and the dynamic of outdoor spaces in the research site.

To gather data from the spaces chosen to be studied, a high definition camera with fisheye lens was set up to collect images in intervals of 10 seconds, from $08 \mathrm{hs} 00$ to $17 \mathrm{hs} 00$, for 10 days over a period of three weeks. The aim was to collect images and then process them both manually, looking for patterns, and then to develop prototypes to automatically process the collected images. As a result, the camera was setup up to take the images according to different intervals, to then be reused in the following steps of the research.

\section{Interviews}

As previously mentioned, interviews were chosen as the second method to gather information from users. The researcher interviewed sixty students around the faculty building to identify if the studied sites were places where students were developing learning activities, what kind of objects they were using during the task, and to comprehend which factors led users to choose these spaces to conduct the activity. The answers given by the users during the interviews then was used as a reference to make a correlation with the data collected over the video recording phase.

During the research process persons interested in taking part in the study voluntary were questioned once over the course of two weeks. The interviews did not last more than fifteen minutes and were done in the field of research (where it is possible to observe patterns of use). The interviews were semi-structured to determine how participants use the campus outdoor spaces according to their learning or recreational goals.

\section{Site observation}

Besides these two methods of data collection, during interviews the site was constantly observed to complement and assist understanding the dynamic of the place. The observations looked at two different hierarchy levels of information during data collection process. On one hand, into focused encounters:

1. How people dispose themselves in relation to each other and space: In Conducting Interaction, Kendon (1990) describes an individual as having a space called a 'transactional segment' into which they typically direct their attention and manipulate objects. According to the author, body arrangement follows implicit rules that will determine how a group of people will behave in space. Kendon (1990) explains that while in a group, people are constantly monitoring and regulating the area and group formation without realizing they are engaged in this process. When someone approaches to participate in a group, bodies will reconfigure to receive the new participant, by increasing the distance between participants and stepping to the side to provide an opportunity for another person to join the formation;

2. What is the user role in the activity: Lawson's research (2001) done in the three main roles in focused encounters (confronting, consorting and co-existing) is used as reference to study users' relationship while they occupy the research site;

3. What kind of object they are holding: This was informed by the work of Gibson (1986) describing 'affordance' as what the environmental structure offers to a particular organism to perform an activity based on the relations between properties of the environment and that organism. Gibson described an affordance as that which an environmental structure offers to a particular organism for activity, based on the relations between properties of the environment and that organism.

On the other hand, the investigation sought for data about the research field dynamic as a whole. In other words, how people flow and encounter one another, leading to activities in the research field and how changes in the environment affect this process. The video data collection, interviews and observation process happened over one month, between March and April 2015, from 08:00 to 17:00. During this period, students are returning to the university to the first semester of the year. In addition, weather is still good enough, providing a comfortable environment to students develop activities in outdoor spaces.

\section{Data analysis}

Data collected during the fieldwork was processed. Interview answers were used to make a correlation between learning and the objects students were using while doing the activity. As will be seen further on, by making this correlation it was easier to track activities using video processing strategies because it is possible to use the own user's answer to identify a pattern of activity, create a prototype, and then gradually add information, improving the system.

Interviews also helped to identify what learning can be, or what students judge to be learning in the context of the University of Melbourne or, more specifically, according to the research site. For instance, answers showed that $80 \%$ of the interviewed users did not considered themselves to be in a learning activity while talking in group. The other $20 \%$, who considered themselves to be engaged in a learning task, 
usually were using an object, such as papers or computer. As a result, the complementary information shows that to classify a group of students developing an activity correlated to learning it is necessary to identify the body formation and the objects that they are using during the activity. In addition, the context where the research site is located is fundamental to correctly classify the patterns of behaviors in outdoor spaces, as long as we judge that students from different faculties in the university can consider different tasks as a learning activity.

After analyzing the results of the interviews, it was possible to draw the following conclusions:

1. Reading potentially correlated to learning: Interviews revealed that $90 \%$ of the students that were reading documents in A4 format (papers or notebooks) and 70\% of students using computers considered themselves to be engaged in a learning activity (these activities were the ones that had higher correlation with learning);

2. Convenient spaces: Students usually use the research site for convenience before classes, for a short period, not only to wait, but also to develop tasks that can be correlated to learning before moving to a lecture. (e.g., reading a paper, writing some notes, or using the computer).

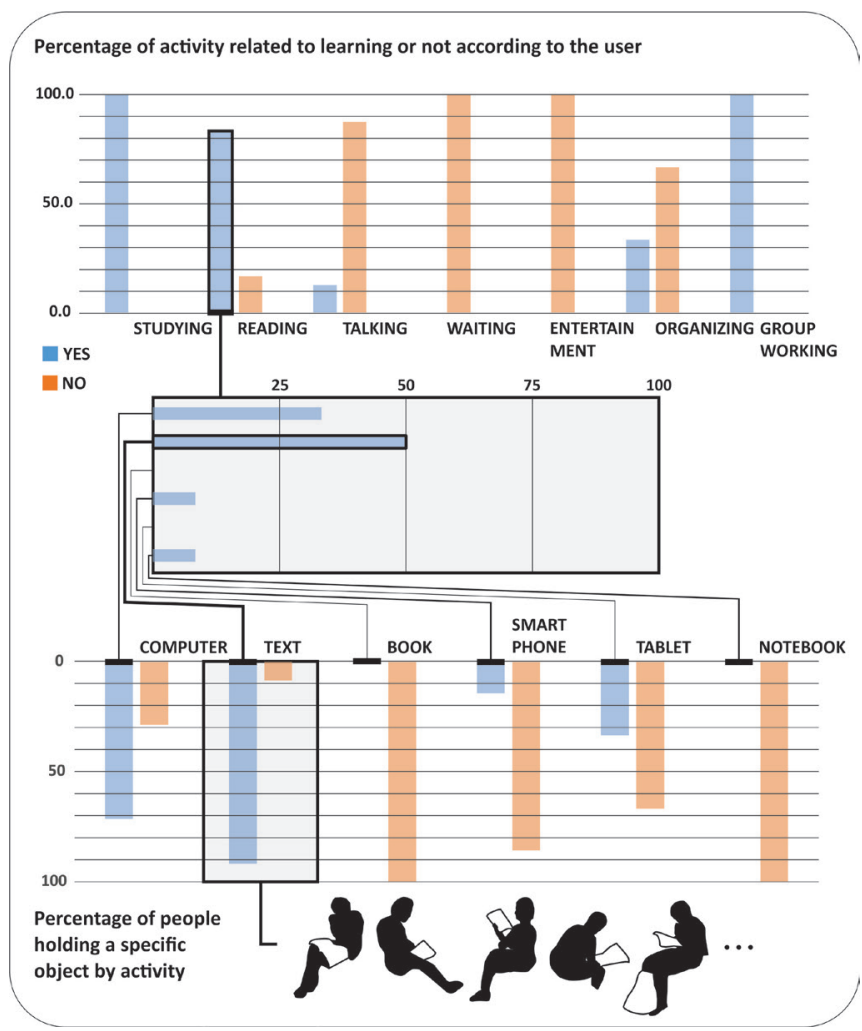

Figure 3: Results obtained from the interview analysis. Source: Created by the author.

In addition to the identification of everyday activities in the research site, the researcher also has manually conducted an analysis of the collected images. As a result, more than 27000 images collected by the time-lapse video were processed, looking for information to validate what the researcher observed in the interviews and data about the research site dynamic. These analyses led to the following preliminary conclusions:

1. Intensity of people's movement: the movement of students in the research changed significantly before the first class in the morning, between classes, lunchtime, and after the last class. It was possible to observe during these intervals more movement of people walking and sitting to talk, eat, read, chatting to a friend, etc.

2. Sitting spots: Students developed tasks, correlated to learning or otherwise, not only on benches but also on the grass lawn located in the south façade of the building. In addition, it was possible to observe that different activities occur simultaneously. In other words, the research site is not a place used exclusively for learning or leisure activities (it is mixed);

3. Concurrently activities: in the research site, activities correlated to learning were happening simultaneously at different intensity. For instance, around a person reading it is likely to be someone doing another activity related to learning, using a computer, talking in a group or reading a text in a tablet. In this case, by tracking the most usual activity, it is possible to perceive the place character as a learning place or not.
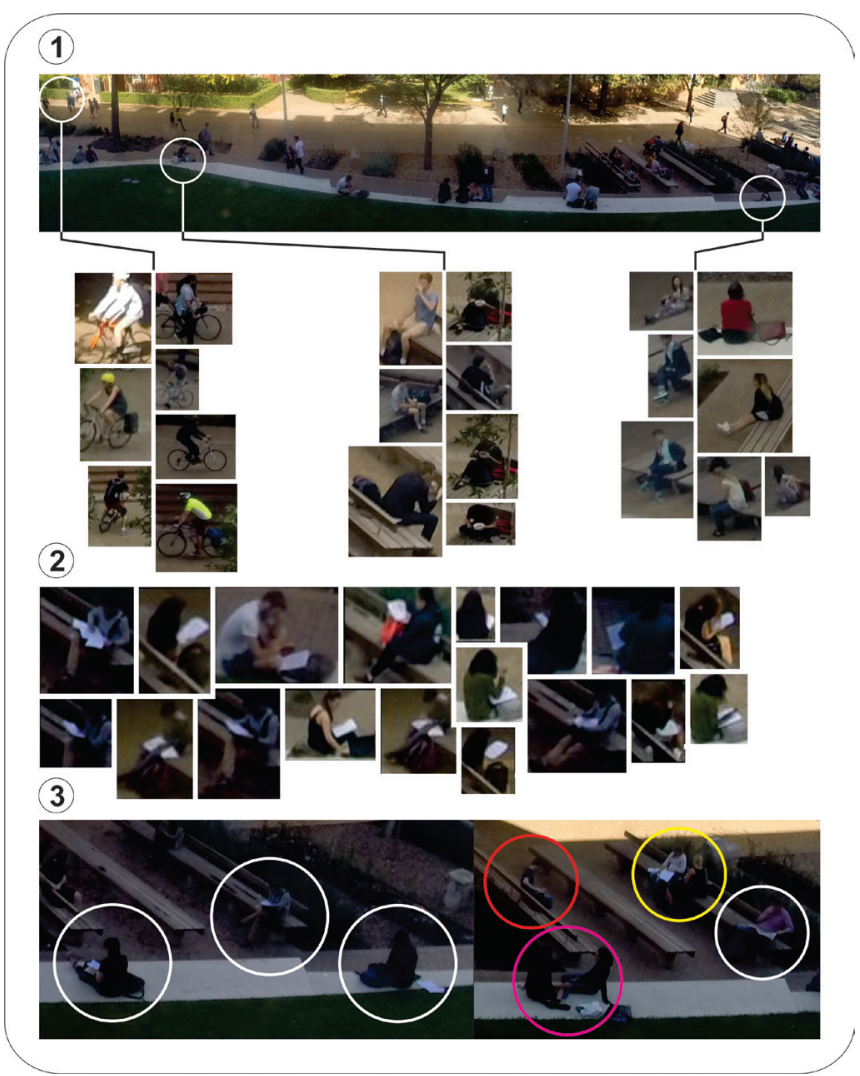

Figure 4: (1) Example of activities identified in the research site and classification; (2) Activity correlated to learning according to interview results; (3) Activities mixed at the same place. Source: Created by the author. 


\section{Development of remote sensing prototypes}

These preliminary conclusions led to the development of three applications, using computer vision methods. The objective was to automate manual analysis that had been done frameby-frame. Each tool had, respectively, the following purposes:

1. Capture intensity of movement: in this case, the goal was to comprehend when the movement of people in the research site increased and decreased over time. From this prototype it is possible to create charts to show the density of people's movement in different parts of the research site during a day or a week. In addition, it is also possible to differentiate areas in the screen, to seek for people, moving, sitting in a bench or sitting in the grass.

2. Identify preferred sitting spots in the studied site: in this prototype, the goal is to create a graphical representation of data to show in a map places where students usually sit more over time in a plan view.

3. Track one activity related to learning: the last prototype has the goal of identifying users developing a specific activity. As previously shown, the research site interviews indicated that students doing this activity in the studied site have a higher probability of considering themselves to be engaged in a learning task. In addition, concurrently to reading, other activities correlated to learning were happening in the place.

The first two prototypes were created in the Processing Integrated Development Environment, using a library of OpenCV (Open Source Computer Vision library) specifically implemented for Processing.

The prototype will be based on the processing of plan and activity recognition formalism given by Sukthankar, Geib, Bui, Pynadath and Goldman (2014). According to the authors, it is always assumed that there is only one person or agent of interest in a scene; however, in many situations in the real world, there are multiple persons performing actions in the same area, or cooperating to perform a group task. Authors explain that the presence of multiple agents can lead to action interdependencies that need to be accounted in order to perform precise recognition.

The pose estimation, defined by Moeslund and Granum (2001) as how a human body and / or individual limbs are configured in a given scene, is a problem that should be solved to assist comprehend human behavior in space. During a specify activity, such as reading or talking in group, the scene can be much more complex and include the pose estimation of other objects in relation to the human body. Usually analytic implementations such the one developed in Tome and Heitor (2012) are intended to track the human body. The results are similar to those obtained in the first two prototypes developed in this research. To move forward and attempt to identify an activity, not directly related to movement or counting people, the results obtained in the manual post processing phase, shows that it is important to make a correlation between the user body and the object he or she is using while developing the activity. The third prototype is still under development and has as a goal tracking the user's body position and the object used by the person to make a correlation and identify the activity.
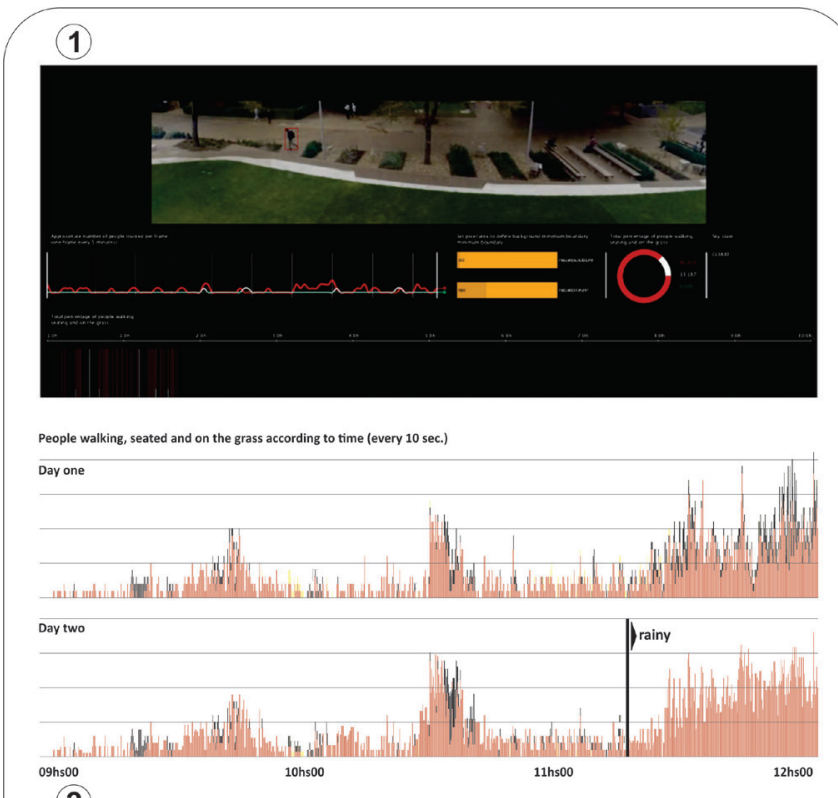

(2)
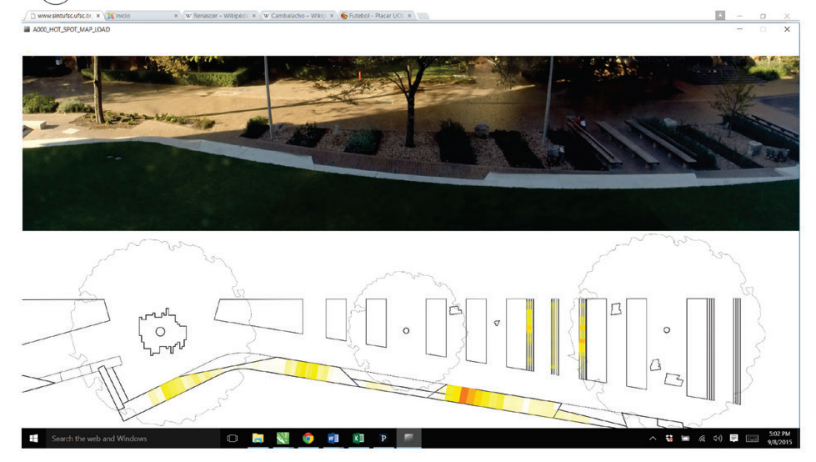

Figure 5: (1) Interface of the prototype to capture people's movement across different areas on the screen; (2) Hot spot map to identify preferred sitting spot in the research site. Source: Created by the author.

\section{PRELIMINARY RESULTS}

From this analysis, is possible to establish a correlation between learning activities and patterns of behavior in outdoor spaces. We note that the interviews were essential to interpret and identify these patterns, because activities developed by users in different places and contexts can lead to different behavior or perception of what constitutes a learning activity. For instance, a student, while talking in group may consider informal talking as learning or, in the context of a university campus, the probability of someone using a computer to be engaged in a learning activity is higher.

After accomplishing the "calibration" using theinterviews as reference, it is possible to remotely sense activities that have greater correlation to learning. Before conducting any remote sensing data collection it is important to identify where learning activities happen, how they happen, ascertain if it is an explicit process or not and define a pattern of occurrence. Nevertheless, objects play an important role 
in the process because the presence of an object assists in identifying activities correlated to learning. For instance, students reading A4 paper are more likely to be engaged in a learning activity than a student who is holding a smartphone. Students working in a group formation, using computer and paper are more likely to be engaged in a learning activity than the group that is only talking informally.

After identifying all patterns, it is possible to use remote sensing strategies to collect data to be analyzed, affording better comprehension of the place usage for a long-term period. The following steps of the research will include the implementation of the third prototype to identify the activity, the position of the user in space and add environmental parameters such as temperature, humidity, wind speed and luminosity to comprehend how activities correlated to learning fluctuate according to changes in the microclimate. This process will lead to guidelines to intervene in outdoor spaces and boost desirable patterns in the campus daily life.

It is important to clarify that this research does not seek to discuss what is and is not learning, because this process can manifest in different ways, sometimes in a more formal and other times in a more informal activity.

\section{Acknowledgments}

We thank the Coordination for the Improvement of Higher Education Personnel (CAPES) for the research grant we received from the program Science without Borders to develop this research at The University of Melbourne.

\section{References}

Bradski, G., Kaehler. A. (2008).Learning OpenCV: computer vision with the opencv library. Cambridge: O'REILLY,

Burlamarqui, L.; Dong, A. (2014). The use and misuse of the concept of affordance. In: Proceedings of the Sixth International Conference on Design Computing and Cognition. London: Springer, 319-338.

Christopher, A. (1979). The timeless way of building. New York: Oxford university press.

Coulson, J. (2015). University trends: contemporary campus design. London: Routledge.

Cleveland, Benjamin William (2011). Engaging spaces: Innovative learning environments, pedagogies and student engagement in the middle years of schools. $\mathrm{PhD}$ dissertation, Faculty of Architecture, Building and Planning, The University of Melbourne.

Dempsey, N., Smith, H., \& Burton, M. (2014). From space to place: The importance of place - keeping. In Place-Keeping: Open Space Management in Practice. Taylor and Francis. 1-12 E. K. M. (1989). Building theories from case study research. The Academy of management review, 14 (4).

Fry, B. (2007) Visualizing Data: exploring and explaining data with the processing environment. Cambridge: O'Reilly Media,.
Gehl, J.; Swarre, B. (2013). How to study public life. Washington: Island Press.

Gibson, J. (1986). The ecological approach to visual perception. Boston: Psychology Press.

Innes, J. E; Booher, D. E. (1997). Metropolitan Development as a Complex System: a new approach to sustainability. Berkeley [Calif.]: University of California at Berkeley, Institute of Urban and Regional Development.

Jamieson, P. (2003). Designing more effective on-campus teaching and learning spaces: a role for academic developers. International Journal for Academic Development, 8, 119-133. Kendon, A. (1990). Conducting interaction: patterns of behavior in Focused Encounters. New York, Cambridge University Press.

Kenney, D. R. (2005) Mission and place: strengthening learning and community through campus design. Westport, CT: American Council on Education and Praeger Publishers. Lawson, B. (2001). Language of Space. Oxford: Architectural Press.

Livingstone, D.W. (2001). Adults' Informal Learning: Definitions, Findings, Gaps and Future Research. Retrieved October 15, 2010.

March, J.; Lave, C. (1975). Introduction to Models in the Social Sciences. New York: HarperCollins.

Mitchell, W. J. (1990). The logic of architecture. Cambridge, Massachusetts: MIT Press.

Moeslund T. B.; Granum, E. A Survey of Computer VisionBased Human Motion Capture. Computer Vision and Image Understanding 81, 231-268 (2001)

Moeslund T. B. (2001). Interacting with a Virtual World through Motion Capture. Virtual interaction: interaction in virtual inhabited 3D worlds. London: IEEE Computer Society Press, 221-234.

Salah A. A.; Gervest, T.; Sebe, N.; Vinciarelli, A. (2010). Challenges of Human Behavior Understanding

Stiny, G. (2006). Shape: talking about seeing and doing / George Stiny. Cambridge, Mass.: MIT Press.

Sukthankar, G.; Geib, C.; Bui, H. H.; Pynadath, D. Goldman, R. P. (2014). Plan, Activity, and Intent Recognition: Theory and Practice. Walthan: Morgan Kaufman.

Tome, A. Heitor, T. (2012). Computer vision of mobility in informal learning spaces. In Proceedings Eighth International Space Syntax Symposium. Edited by M. Greene, J. Reyes and A. Castro. Santiago de Chile: PUC.

Wang, D., Groat, L. N. (2002). Architectural research methods. New Jersey, John Wiley and Sons.

:Whyte, William Hollingsworth (1980). The social life of small urban Spaces. Washington, D.C.: Conservation Foundation, 1980

THE social life of small urban Spaces (1988). Direction: William Hollingsworth Whyte, Washington, Direct Cinema Limited.

Zhan, B., Monekosso, D. N., Remagnino, P., Velastin, S. A.; XU, L. (2008). Crowd analysis: a survey Machine Vision and Applications, 19, 345-357 